\title{
Role of Propolis in Osteointegration Enhancement in Allograft Autoclaved Implanted in Femur of Dogs \\ Abdellatif Boudra ${ }^{1 *}$, Mohamed Hamdi² and Karim Amara ${ }^{2}$
}

${ }^{1}$ Veterinary institute, Ibn khaldoune university of TIARET, Senior veterinary of Mahassil company NH group, Algeria

${ }^{2}$ Ibn khaldoune university of TIARET, Veterinary institute, Algeria

\begin{abstract}
The orthopedic surgeon is often faced with the loss of bone substance indiaphyseal region of long bones. Our study is based on a biological approach to the filling of segmental bone loss by implanting an autoclaved orthotopic allograft of one centimeter length covered and uncovered with propolis in the femoral diaphysis. The experiment involved eight adult dogs, from local breed and different sex; split into two groups. An autoclaved allograft without propolis was implanted for the first animals group then the same graft this time covered with a thin layer of propolis has been implanted to the second animals group. The aim of our study is to determine if the propolis accelerates the osteointegration of the allograft covered with propolis, to follow up that process radiologically until obtaining a total consolidation. The results show that the use of a graft covered with propolis enhance and accelerate the osteointegration process; it has been demonstrated by an early passage of the callus at both proximal and distal interfaces, with an average duration of four weeks and eight weeks respectively.
\end{abstract}

Keywords: Propolis; Autoclaved allograft; Interface; Osteointegration; Radiography; Proximal interface; Distal interface

\section{Introduction}

The treatment of bone loss with a graft is underestimated; however it can potentially help patients achieve a faster return to normal activities [1]. The bone graft is a ubiquitous material in orthopedic surgery since it is used in all subspecialties and majorities of anatomical regions [2]. Even today, autologous transplantation remains the reference method, despite its disadvantages (increased duration of intervention and surgical risk, residual pain, limited quantity) [3]. The allograft is an alternative to the massive segmental bone loss but often faces several constraints, including the problem of infection, failure of incorporation and the decrease with time of mechanical properties resulting in the fracture of the graft [4]. Health industry has always used the natural product as an alternative [5], currently; the propolis is studied due to its ability to improve the regeneration of bone loss [6].

\section{Materials and Methods}

\section{Experimental animals}

Our experiment was conducted on eight (08) local breed dogs (male and female) aged between 6 and 12 months, the average body weight is estimated at $15 \mathrm{~kg}$. All animals were dewormed by using Flubendazole at $75 \mathrm{mg} / \mathrm{kg}$ (FLUVERMAL ${ }^{\circledR}$; Janssen-Cilag; France; 100 $\mathrm{mg}$ /comprimé) and a control collar was secured around dog's neck to prevent infestation of external parasites. Thereafter, the animals were placed in separate cages and left for an accommodation period of 15 days. Preparation of orthotopic allografts put in special bags has required the use of an autoclave and a pure extract of propolis and the radiographic monitoring was performed using digital radiology.

\section{Graft preparation}

The graft is obtained from the diaphysis of the left femur of a dog euthanized, after removal of the periosteum, bone and muscle insertions of residues, and the shaft is cut by using a stainless metal saw into fragments of $1 \mathrm{~cm}$ length. The grafts in the control group are put directly in special sealed bags (SteriClean ISO 11607 REF 230112 LOT $300671506201120 \mathrm{~cm} / 200 \mathrm{~m}$ ). Other grafts are similarly prepared, except an additional step where the sold Propolis extract (maltodextrine), Cellulose,anticaking agent: Magnesium Stearate (Arkogélule Arkopharma 45 capsules 22.3 gr, 250 mg/capsule France $\mathrm{N}^{\circ}$ de lot $\left.\mathrm{BCP} 00865 \mathrm{~B}\right)$ is applied to the integrity of the graft before it is placed in bags for sterilization. The grafts are prepared then autoclaved at a temperature of $121^{\circ} \mathrm{C}$ (Webeco $\mathrm{GmbH}$ type A $\mathrm{N}^{\circ} 919995$ made in Germany Watt 2700 Amp 12).

\section{Anesthetic protocol}

Anesthetic premedication protocol is begun with $0.01 \mathrm{mg} / \mathrm{Kg}$ atropine injected subcutaneously (Atropine ${ }^{\circledR}$ sulfate $(0,1 \%)$ : Lab RENAUDIN; $\mathrm{N}^{0}$ 112992; France), followed after 15 minutes by a double injection intramuscularly of acepromazine (CALMIVET $^{\mathbb{B}}$ (0.5\%): Vetoquinol; France) and buprenorphine (Temgesic ${ }^{\circledR}(0,3 \mathrm{mg} /$ $\mathrm{ml}$ ): Scheringplough; Levallois-Perret; France)at $0.2 \mathrm{mg} / \mathrm{kg}$ and 0,02 $\mathrm{mg} / \mathrm{Kg}$ respectively. Induction is achieved by a single slow intravenous injection of propofol in an amount of $8 \mathrm{mg} / \mathrm{Kg}$.Just before starting the operation, half mixture of tiletamine and zolazepam at a rate of $15 \mathrm{mg} /$ $\mathrm{kg}$ was injected to maintain anesthesia during surgery, the second half was injected 45 minutes after and if necessary of small amounts may be added throughout the operation.

\section{Surgical technique}

The spindle is inserted through the proximal end with a mandrel Jacobson, it engages retrogradely into the medullary canal of the proximal portion held by a clamp to bone, the diameter of the pin must

${ }^{*}$ Corresponding author: Abdellatif Boudra, Veterinary institute, Ibn khaldoune university of TIARET, Senior veterinary of Mahassil company NH group, Algeria, Tel: +213-(0)46-42-50-01; E-mail: afboudra@gmail.com

Received March 10, 2014; Accepted May 09, 2014; Published May 12, 2014

Citation: Boudra A, Hamdi M, Amara K (2014) Role of Propolis in Osteointegration Enhancement in Allograft Autoclaved Implanted in Femur of Dogs. J Veterinar Sci Technol 5: 173. doi:10.4172/2157-7579.1000173

Copyright: ( 2014 Boudra A, et al. This is an open-access article distributed unde the terms of the Creative Commons Attribution License, which permits unrestricted use, distribution, and reproduction in any medium, provided the original author and source are credited. 
represent $50-70 \%$ of the medullary cavity. The pin is slid along the medullary canal until the trochanteric fossa, a skin incision is made at the raised portion by the spindle and it outputs the three quarters of the pin through this opening. Once the proximal and distal portion of the bone are drilled using a Steinmann pin $2 \mathrm{~mm}$ diameter, in order to get the stainless wire of $0.6 \mathrm{~mm}$ in diameter to produce a hemi strapping. The complete insertion of the pin is estimated by a spindle of the same length in parallel with the pin lodged down, thereafter, the remainder thereof is cut with a cutting spindle. The next step comprises applying a powder of antibiotic at both wound and then the fascia suture overlock a synthetic absorbable suture with polyglactin $0 / 2$. The closure of the skin is ensured by simple points separated polyamide $0 / 2$ and the wound is cleaned with betadine. After injection of an analgesic, the animal is monitored until awakened, then placed in an individual cage in order to limit the movements.

\section{Radiological monitoring}

Digital radiography (Camera Digital Radiography RAD-12 X-RAY Tube made for General Electric Company, Model 226680 serial 50431HL6, USA) performed each fifteen (15) days will allow us to assess the quality the callus, and the fate of the graft until withdrawal of spindle. Radiographs are taken in side view, to properly highlight the femur. The animal is sedated lying on the operated side with the nose gear rotated $45^{\circ}$. The free member is held vertically.

\section{Discussion}

Propolis extract has already demonstrated its efficiency, especially with the non-existence of side effects and adverse drug reaction following its use. $0.5-1 \%$ of the solutes was administered as an aerosol for the treatment of acute and chronic respiratory diseases and even as eye drops. $10 \%$ alcoholic solutions have been used indisinfecting hands in the practice of dentistry. The beneficial effects of propolis appear to beworthy of their therapeutic efficiency [7], the introduction of propolis in our study has opened new perspectives for the use of this substance in orthopedic surgery, the results of the clinical followup showed a recovery of all dogs treated with propolis graft covered with a minimum of post-operative complications. The propolis extracts showed a regenerative power with regard to bone and cartilage, this is also a property of flavonoids which have anti-inflammatory action and have the potential to stimulate the development of collagen [6]. Propolis also helps in the development of bone bridge, it proved stimulating various enzyme systems, cell metabolism, circulation and collagen development [5], Radiological results obtained (Table 1) show that the device in cases where callus autoclaved allogeneic grafts are covered with propolis was formed directly on the graft (Figures 1 and 2 ); while the callus where the grafts are uncovered formed remote from the graft. The same results have shown that the stimulation of bone formation by propolis is causing the complete transition callus through

\begin{tabular}{|l|c|c|}
\hline \multicolumn{2}{|c|}{ Animals and type of graft } & Cal position \\
\hline \multirow{4}{*}{ Graftwithout propolis } & $\mathrm{N}^{\circ} 1$ & Far graft \\
\cline { 2 - 3 } & $\mathrm{N}^{\circ} 2$ & Far graft \\
\cline { 2 - 3 } & $\mathrm{N}^{\circ} 3$ & Far graft \\
\hline \multirow{3}{*}{ Graftwith propolis } & $\mathrm{N}^{\circ} 4$ & Far graft \\
\hline
\end{tabular}

Table 1: Evolution of radiological callus.

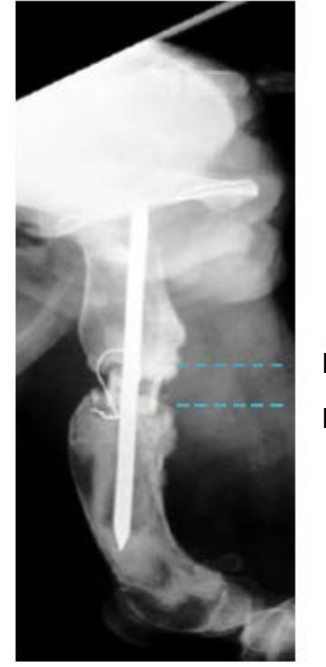

Figure 1: Radiography at 45 days shows cal approximation of the 2 interfaces and a graft that does not have any deformation (case $\mathrm{N}^{0} 4$ graft covert with propolis ).

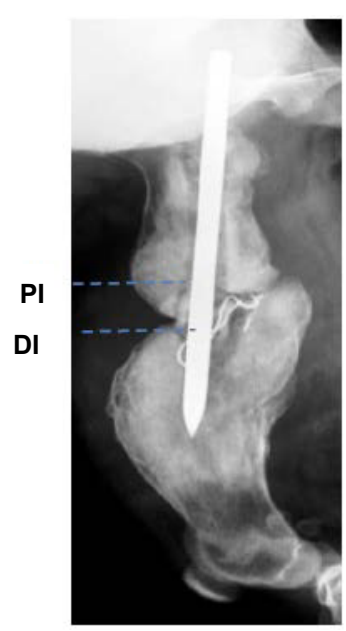

Figure 2: The radiography at75 days shows,complete consolidation of callus on the 2 interfaces, the graft is still in place and does not have any modification noted (case $\mathrm{N}^{0} 1$ graft covert with propolis ).

both interfaces, unlike the control group where the callus moved to a limit not exceeding the limit of the graft Figure 3. Osteoclasts, supplied by the vasculature, provide the resorption of necrotic bone. This step of the graft incorporation is the most important first eight (08) weeks of its establishment. The porosity increases the resorption of the graft decreases and therefore its mechanical strength. That is why it is estimated that the critical period of a strength point of view lies between the (06th) and the sixth week (06th) six months after transplantation.

Generally healing allograft host interfaces occurs in a longer time than autografts: Fifteen weeks against twelve weeks for the proximal interface and eighteen weeks instead of twelve to the distal interface $[8,9]$. As per the results of our study (Table 2), the use of autoclaved allogeneic graft covered with propolis led to a complete transition to eight weeks of callus at the distal interface and four to six weeks for the proximal interface (case No 1, 2 and 4). Full consolidation of the callus 


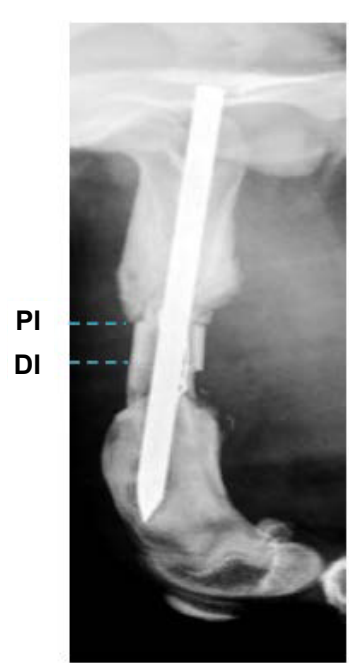

Figure 3: Radiograpy at 30 days shows the progress of the callus of the 2 interfaces, the graft is still in place and kept the integrity of its cordical (case $\mathrm{N}^{0}$ 3 graft without propolis).

\begin{tabular}{|c|c|c|c|c|}
\hline \multirow{2}{*}{\multicolumn{2}{|c|}{ Animals and type of graft }} & \multicolumn{2}{|c|}{ Duration of callusdevelopment } & \multirow{3}{*}{$\begin{array}{c}\text { full consolidation } \\
\text { / }\end{array}$} \\
\hline & & \multirow{2}{*}{$\begin{array}{c}\text { Proximal } \\
\text { interface } \\
/\end{array}$} & \multirow{2}{*}{$\begin{array}{c}\text { Distal interface } \\
/\end{array}$} & \\
\hline \multirow{4}{*}{$\begin{array}{l}\text { Graft without } \\
\text { propolis }\end{array}$} & $N^{\circ} 1$ & & & \\
\hline & $\mathrm{N}^{\circ} 2$ & l & 1 & l \\
\hline & $N^{\circ} 3$ & l & l & l \\
\hline & $N^{\circ} 4$ & 10weeks & 12weeks & +12 weeks \\
\hline \multirow{4}{*}{$\begin{array}{l}\text { Graft } \\
\text { propolis }\end{array}$} & $N^{\circ} 1$ & 6 weeks & 8 weeks & 10 weeks \\
\hline & $\mathrm{N}^{\circ} 2$ & 4 weeks & 8 weeks & 10 weeks \\
\hline & $N^{\circ} 3$ & 12 weeks & 12 weeks & +12 weeks \\
\hline & $N^{\circ} 4$ & 6 weeks & 8 weeks & 10 weeks \\
\hline
\end{tabular}

Table 2: Monitoring the evolution of radiological callus. at both cranial and caudal faces was obtained after ten to twelve weeks (case $\mathrm{N} 1,2$ ).

\section{Conclusion}

Our study confirms that the use of a thin layer of commercial extract propolis on an autoclaved allograft enhanced and accelerated the osteointegration at both proximal and distal interfaces before failure of the allograft. The extract of propolis helped for the obtaining of the full consolidation at ten to twelve weeks before the remodeling operation starting of the new bone and of the former haversian system (allograft) resorption.

\section{References}

1. Miller LE, Block JE (2011) Prospective on the clinical utility of allograft for bone regeneration with osseous defects,Orthopedic Research and Reviews, 3: 31 37.

2. Markel DC, Guthrie ST, Wu B, Song Z, Wooley PH (2012) Characterization of the inflammatory response to four commercial bone graft substitutes using a murine biocompatibility model. J Inflamm Res 5: 13-18.

3. Razafimhandry HJC, Randrianasolo $\mathrm{D}$, Andriamanana NW, Randriarimangan RHB (2001) Both use natural coral as a bone substitute, medicine Africa Black, 48: P114.

4. Amorosa LF, Lee CH, Aydemir AB, Nizami S, Hsu A, et al. (2013) Physiologic load-bearing characteristics of autografts, allografts, and polymer-based scaffolds in a critical sized segmental defect of long bone: an experimental study. Int J Nanomedicine 8: 1637-1643.

5. Parolia A, Thomas S, Kundabala M, Mohan M (2010) Propolis and its potential uses in oral health, Intern.J. Med. Medical. Sciences, 2: 210-215.

6. Andrade AL, Manzi D, Zdomingues R (2006) Tetracycline and Propolis incorporation and release by bioactive glassy compounds, Science Directe, $J$ Non-Crystalline Solids, 352: 3502-3057.

7. Grange JM, Davey RW (1990) Antibacterial properties of propolis (bee glue). J R Soc Med 83: 159-160.

8. Mathon D (2002) Grafts and bone substitutes, CES musculoskeletal trauma and animal orthopedics, Pp18-22.

9. Schena CJ, Mitten RW, Haefle WD (1984) Segmental freeze dried and Fresh cortical allograft in canine femur 1 , A sequential radiographic comparison over a one-year time interval, J. Am. Anim. hosp. Assoc, 20: 911-925. 